This is a revised personal version of the text of the final journal article, which is made available for scholarly purposes only, in accordance with the journal's author permissions. The full citation is:

Heaven S, Salter A M, Clarke D (2007) "Influence of annual climate variability on design and operation of waste stabilisation ponds for continental climates", Water Science \& Technology Vol 55 No 11 pp 37-46 C IWA Publishing 2007 doi:10.2166/wst.2007.368 doi 10.2166/wst.2007.368 http://www.iwaponline.com/wst/05511/wst055110037.htm

\title{
Influence of annual climate variability on design and operation of waste stabilisation ponds for continental climates
}

\author{
S. Heaven*, A. M .Salter*, D. Clarke* \\ * School of Civil Engineering and the Environment, University of Southampton, Southampton, SO17 1BJ, UK \\ (E-mail: sh7@soton.ac.uk)
}

\begin{abstract}
WSPs are widely used in North America, and offer huge potential for other continental climate regions. The standard design and operating protocol is robust even at high latitudes, but may be conservative elsewhere. A simple model based on first-order kinetics for biochemical oxygen demand (BOD) is used to consider some alternative design and operating protocols, using long-term daily climate records for cities across continental central asia. Options include changing the discharge period; retaining treated water in the pond over the winter; and changing the facultative pond loading. Annual variability in climate parameters has a major effect, in particular on the date at which treated wastewater meets appropriate standards for discharge or re-use: the earlier the discharge, the greater the variability in effluent quality. Skilful management of these systems may therefore be required to maximise their performance. While current models require development, it is clear modelling could provide tools and guidelines that would allow the design of continental climate WSP to be tailored to specific regional and local climate conditions.
\end{abstract}

Keywords continental climate, waste stabilisation ponds, wastewater reuse

\section{INTRODUCTION}

Waste stabilisation ponds (WSPs) are widely used in Canada and the northern states of the USA, and offer enormous potential for other continental climate regions. The recommended standard design in North America is the intermittent discharge system, based on treatment combined with storage for 12 months, followed by release over a short period in autumn (Prince et al., 1995). This approach has proven successful even at high latitudes, but may be conservative when applied in more southerly areas. The operating mode also assumes that discharge will be to a large watercourse, at a time when effluent quality is high and sufficient flow is available for dilution. In the extreme continental climates of southern central Asia, however, the sharp improvement in effluent quality noted at the onset of autumn in colder climates may not occur. In addition, these regions are typically arid or semi-arid: in some areas perennial water courses suitable for receiving a discharge may not exist, and the overall scarcity of water resources makes re-use of much greater importance. Climates of this type stretch from China and Mongolia across central Asia and southern Russia to the Caspian and beyond. In the more extreme locations, populations have historically been small: but factors such as economic development in western China mean that increasing numbers now live in these areas, creating a growing need for effective technology of this type. 
Heaven et al. (2005) suggested that alternative WSP design and operating protocols should be developed for these regions, to make more effective use of the treatment capacity present in the warm summer period. Since the transition from accumulation of load in winter to rapid breakdown in spring and summer is driven by climatic factors, however, annual variation in these is likely to be critical to any modified design or operating protocol. The paper looks at some effects of annual variability in climate parameters across continental Asia, using a simple model to allow prediction of the effects on pond performance.

\section{MATERIALS AND METHODS}

Model construction and assumptions. The model is based on that described in Heaven et al (2005), and simulates a WSP system consisting of a facultative pond (FP) and a storage/maturation pond (SMP). The original spreadsheet-based model was extended using a Microsoft Visual Basic program to allow automated analysis with climate data for multi-year sequences. The model calculates mass balances for wastewater volumes and biochemical oxygen demand (BOD), or any similar degradable component, using a one-day time-step. Wastewater volumes are calculated taking into account inflow, outflow, evaporation and precipitation and assuming no infiltration. The ponds are assumed to be simple rectangles in plan, with no allowance for variation of area with depth and side slope. BOD concentrations are calculated assuming first-order decay kinetics. The decay constant $k$ is assumed to follow an Arrhenius equation of the form $k_{\mathrm{T}}=k_{20} \theta^{(\mathrm{T}-20)}$, where $k_{\mathrm{T}}$ and $k_{20}$ are values of $k$ at temperatures of $\mathrm{T}^{\circ} \mathrm{C}$ and $20{ }^{\circ} \mathrm{C}$ respectively.

The FP is sized according to the areal loading rate (US EPA, 1983), by specifying a BOD surface loading rate and a working depth, and thus fixing the surface area, volume and mean hydraulic retention time for a given inflow and influent BOD concentration. Once the surface area is known, daily and total outflows are calculated based on inflow minus evaporation and precipitation. The mass of BOD in the pond is calculated based on the initial value, inputs, decay and discharge, and daily effluent concentrations are obtained by dividing the total mass of BOD by the pond volume.

The design of the SMP is defined by choosing a maximum and minimum depth and a discharge period, at the end of which the depth is assumed to be at its minimum. The outflow from the SMP is equal to inflow (corresponding to outflow from the FP minus any direct discharges), minus evaporation and plus precipitation. As precipitation and evaporation inputs depend on the surface area, any change in area alters the maximum volume to be stored in the SMP. In order to establish the required area for a given maximum and minimum depth, the model is run with an initial estimate of area. If the calculated pond depth at any point in the simulation is greater than the maximum value, the area is incremented and the calculations repeated. This process is iterated until the entire dataset can be analysed without exceeding the maximum depth. Outflow from the SMP is calculated based on discharge over a fixed period that starts and finishes on the specified dates each year. The daily outflow is calculated as the volume contained in the SMP at the start of each day divided by the number of days remaining over which it is to be emptied. As evaporation and precipitation vary each day, the amount to be discharged also varies and needs to be recalculated on a daily basis. Daily values are then used to calculate pond depth and effluent BOD concentrations.

The validity of specific output values for BOD is uncertain, for reasons discussed briefly below and in Heaven et al. (2005); but the model results are adequate to indicate key factors and trends. 
Climate data. Records of temperature and precipitation for twelve cities across the central Asian region were taken from the archive of the All-Russia Research Institute of Hydrometeorological Information - World Data Centre (RIHMI-WDC, 2006). The datasets consist of daily records, starting in some cases from the 1880 s, but with some years missing or only partially complete. As the model requires data from complete years, any years with missing periods of more than 5 continuous days were eliminated. Where data were missing for 5 days or less, temperature values were interpolated from adjacent days. Missing precipitation values were assumed to be zero. For evaporation, Penman-based estimates for reference crop evapotranspiration were obtained from the International Water Management Institute climate database (IWMI, 2006). These monthly values were converted by polynomial interpolation to daily potential evapotranspiration $\left(\mathrm{ET}_{\text {wat }}\right)$ for open water less than $2 \mathrm{~m}$ deep, using a factor of 1.05 (Allen et al, 1998). Water temperature was assumed to equal mean daily air temperature down to $0{ }^{\circ} \mathrm{C}$ and to remain at zero for lower air temperatures, with a 5-day time lag. Details of weather stations and climate data used are given in Table 1.

Table 1 Weather stations and climate data used in modelling

\begin{tabular}{|c|c|c|c|c|c|c|c|c|c|c|}
\hline Site & Latitude & Longitude & Altitude & Country & Period & & Full data & Days $<0^{\circ} \mathrm{C}$ & $\mathrm{ET}_{\text {wat }}$ & Precipitation \\
\hline & ${ }^{\circ} \mathrm{N}$ & ${ }^{\circ} \mathrm{E}$ & $\mathrm{m}$ & & from & to & years & & $\mathrm{mm}$ & $\mathrm{mm}$ \\
\hline Khorog & 37.3 & 71.3 & 2080 & Tajikistan & 1899 & 1994 & 93 & 97 & 1252 & 254 \\
\hline Ashkhabad & 38.0 & 58.3 & 208 & Turkmenistan & 1938 & 1995 & 52 & 22 & 1490 & 230 \\
\hline Yerevan & 40.1 & 44.5 & 907 & Armenia & 1886 & 1991 & 89 & 68 & 1134 & 295 \\
\hline Bishkek & 42.8 & 74.5 & 760 & Kyrghyzstan & 1936 & 1991 & 56 & 75 & 1163 & 413 \\
\hline Turkestan & 43.3 & 68.2 & 207 & Kazakhstan & 1886 & 1995 & 94 & 70 & 1556 & 186 \\
\hline Atyrau & 47.1 & 51.9 & 23 & Kazakhstan & 1881 & 1995 & 94 & 116 & 1337 & 159 \\
\hline Aktyubinsk & 50.3 & 57.2 & 219 & Kazakhstan & 1905 & 1995 & 78 & 150 & 1009 & 269 \\
\hline Astana & 51.2 & 71.4 & 350 & Kazakhstan & 1882 & 1995 & 100 & 167 & 962 & 289 \\
\hline Ulan Ude & 51.8 & 107.6 & 515 & Russia & 1887 & 1995 & 100 & 178 & 721 & 248 \\
\hline Petropavlovsk & 54.8 & 69.2 & 142 & Kazakhstan & 1901 & 1993 & 78 & 169 & 756 & 346 \\
\hline Krasnoyarsk & 56.0 & 92.5 & 276 & Russia & 1915 & 1995 & 78 & 168 & 616 & 431 \\
\hline Yakutsk & 62.0 & 129.7 & 101 & Russia & 1889 & 1995 & 98 & 210 & 556 & 210 \\
\hline
\end{tabular}

Modelling parameters and scenarios. Wastewater inflow rates were taken as $1000 \mathrm{~m}^{3}$ day $^{-1}$, with a BOD of $200 \mathrm{mg} \mathrm{l}^{-1}$. BOD decay constant values were $\theta_{\mathrm{BOD}}=1.08$ and $k_{20}$ BOD $=0.25$ (Mara, 1976). For modelling purposes, wastewater was considered nominally acceptable for discharge when the 95-percentile BOD concentration reached $20 \mathrm{mg} \mathrm{l}^{-1}$. The standard design was based on working depths of $1 \mathrm{~m}$ for the FP and $2 \mathrm{~m}$ for the SMP; a FP surface loading rate of $40 \mathrm{~kg} \mathrm{BOD} \mathrm{ha}^{-1} \mathrm{day}^{-1}$; and a single autumn discharge. Other cases considered included discharge from the SMP with different durations, start dates, and volumes of over-winter storage; and alternative FP loading rates.

\section{RESULTS AND DISCUSSION}

\section{Sites and climate parameters}

The sites were chosen to provide a range of latitudes and conditions, and for the quality of their data records, rather than any specific need for or association with WSP systems. In Ashkhabad mean winter temperatures are sufficiently high that in most years ponds are unlikely to freeze: but the dataset shows an average of 22 and a maximum of 61 days each year below zero, including continuous periods of over a month. Khorog is at the southern limit of the group, but experiences freezing temperatures due to its altitude. Yakutsk is too far north for potential re-use of treated wastewater in irrigation: in practice large-scale agriculture ceases around $55{ }^{\circ} \mathrm{N}$, but the site was included to provide an example of high 
latitude parameters. Figure 1 shows examples of climate data for selected sites: all are typified by large variation in summer and winter temperatures, with especially high variability in spring and autumn. Sites in the middle and northern latitudes (Atyrau, Astana, Petropavlovsk) are characterised by a skewed temperature distribution in winter: there are many low values but a long period in which maximum mean daily temperatures seldom exceed zero, followed by a sudden sharp increase. All of the sites are quite dry (Table 1), but there are also differences in the distribution of precipitation through the year, which have considerable significance for potential re-use in agriculture or river recharge. Figure 1 gives examples of three typical modes for average daily precipitation and $\mathrm{ET}_{\text {wat }}$ for the period covered by each dataset. In the south summers are very dry, and precipitation occurs in the winter (Khorog, Ashkabad, Turkestan) or bi-modally in spring and autumn peaks (Erevan, Bishkek). In the north (Astana, Krasnoyarsk, Petropavlovsk, Ulan Ude, Yakutsk) precipitation occurs as rain in summer; while in mid-latitudes (Atyrau, Aktyubinsk) rainfall is more evenly distributed through the year.

\section{Modelling results}

The distribution of calculated effluent concentrations on a given date was found to be log normal, while the date on which the calculated concentration reached a given value each year was approximately normally distributed.
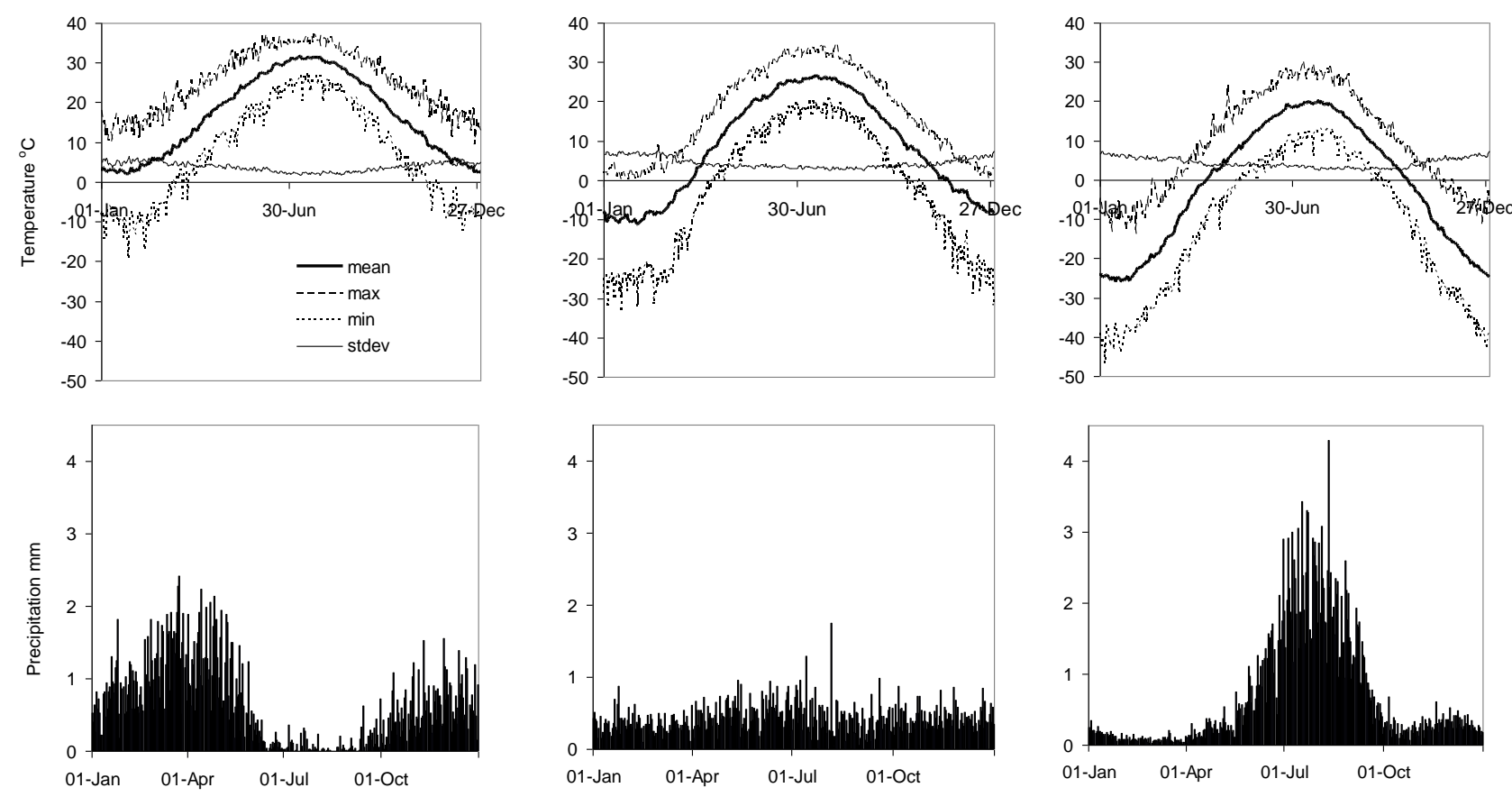

ii) Atyrau

iii) Ulan Ude

Figure 1 Mean, max and min daily temperatures and mean daily rainfall, for selected sites

Standard design. Table 2 shows key output parameters for a standard design at each site, assuming discharge from 1-30 October and maximum and minimum SMP depths of $2.5 \mathrm{~m}$ and $0.5 \mathrm{~m}$. Examples of SMP effluent BOD concentrations for selected sites are shown in Figure 2. Overall the results indicate that the classic north American design is robust in terms of the likelihood of achieving low concentrations by the discharge period, and annual variations in climate are unlikely to have much impact on water quality in late summer. There is little or no carry-over in performance from year to year, as the sequence is broken by the long summer retention period in which effluent concentrations reach a steady-state value; in 
northern areas, a similar effect may also arise from the period of minimal treatment in winter. This implies that the fact that continental climates are subject not only to extreme variations but also to sequences of wet or dry and warm or cold years is not likely to be critical to WSP design. The fact that the nominally acceptable quality is generally achieved much earlier than the actual discharge date suggests, however, that the systems are over-designed, leading to unnecessarily large ponds and high evaporative losses due to the long storage of treated wastewater. For the standard design at the chosen sites, approximately $73 \%$ of variation in the day of discharge is accounted for by latitude, rising to 85\% if Khorog (altitude $2080 \mathrm{~m}$ ) is omitted; latitude also accounts for about $56 \%$ of variation in required pond size.

Table 2 Model output for standard design with discharge from 1-30 October

\begin{tabular}{|c|c|c|c|c|c|c|c|c|c|c|c|c|}
\hline \multirow[t]{3}{*}{ Site } & \multicolumn{5}{|l|}{ Days } & \multicolumn{5}{|c|}{ Concentration } & \multirow{3}{*}{$\begin{array}{c}\text { Area } \\
F P+S M P \\
\text { ha }\end{array}$} & \multirow[t]{3}{*}{$\%$ for use } \\
\hline & \multicolumn{4}{|l|}{ Start } & \multirow{2}{*}{$\begin{array}{l}\text { End } \\
95 \% \text { ile }\end{array}$} & \multicolumn{4}{|c|}{ Start } & \multirow{2}{*}{$\begin{array}{l}\text { End } \\
95 \% \text { ile }\end{array}$} & & \\
\hline & Mean & $95 \%$ ile & Day & Range & & Mean & $95 \%$ ile & Day & Range & & & \\
\hline Khorog & 22-Apr & 09-May & 128 & 17 & 21-Nov & 24-Apr & 06-May & 125 & 12 & 03-Dec & 15.9 & $57 \%$ \\
\hline Ashkhabad & - & - & 1 & - & - & - & - & 1 & - & - & 14.6 & $60 \%$ \\
\hline Yerevan & 25-Mar & 22-Apr & 111 & 28 & 19-Dec & 01-Apr & 21-Apr & 110 & 20 & 19-Dec & 16.3 & $55 \%$ \\
\hline Bishkek & 17-Mar & 09-Apr & 98 & 23 & 13-Jan & 22-Mar & 10-Apr & 99 & 19 & 06-Dec & 17.2 & $53 \%$ \\
\hline Turkestan & 20-Mar & 15-Apr & 104 & 26 & 12-Nov & 26-Mar & 12-Apr & 101 & 17 & 03-Dec & 13.5 & $63 \%$ \\
\hline Atyrau & 26-Apr & 16-May & 135 & 20 & 29-Dec & 30-Apr & 13-May & 132 & 13 & 20-Nov & 14.5 & $60 \%$ \\
\hline Aktyubinsk & 14-May & 26-May & 145 & 12 & 06-Nov & 16-May & 26-May & 145 & 10 & 12-Nov & 16.7 & $54 \%$ \\
\hline Astana & 23-May & 04-Jun & 154 & 12 & 09-Nov & 25-May & 04-Jun & 154 & 10 & 11-Nov & 18.0 & $51 \%$ \\
\hline Ulan Ude & 05-Jun & 11-Jun & 161 & 6 & 04-Nov & 06-Jun & 12-Jun & 162 & 6 & 05-Nov & 18.7 & $49 \%$ \\
\hline Petropavlovsk & 27-May & 07-Jun & 157 & 11 & 12-Nov & 26-May & 07-Jun & 157 & 12 & 11-Nov & 19.7 & $46 \%$ \\
\hline Krasnoyarsk & 26-May & 06-Jun & 156 & 11 & 09-Nov & 27-May & 06-Jun & 156 & 10 & 13-Nov & 20.8 & $43 \%$ \\
\hline Yakutsk & 18-Jun & 23-Jun & 173 & 5 & 01-Nov & 19-Jun & 26-Jun & 176 & 7 & 30-Oct & 18.9 & $48 \%$ \\
\hline
\end{tabular}

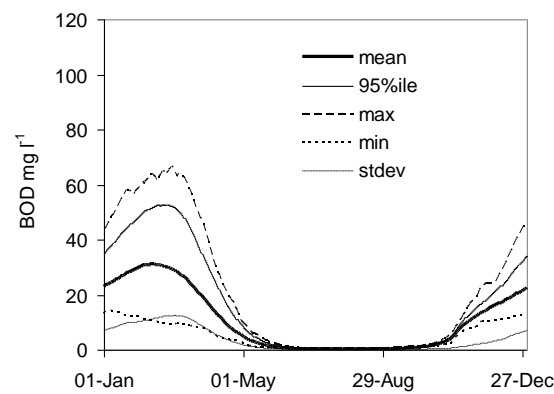

a) Turkestan

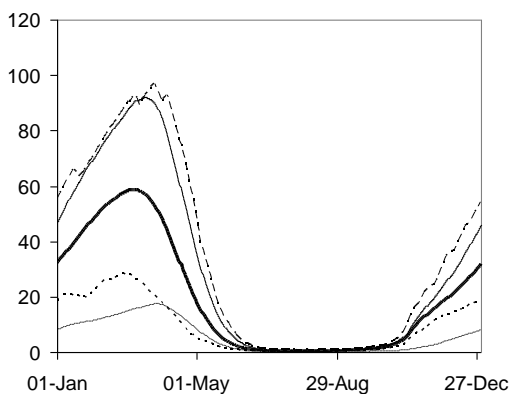

b) Atyrau

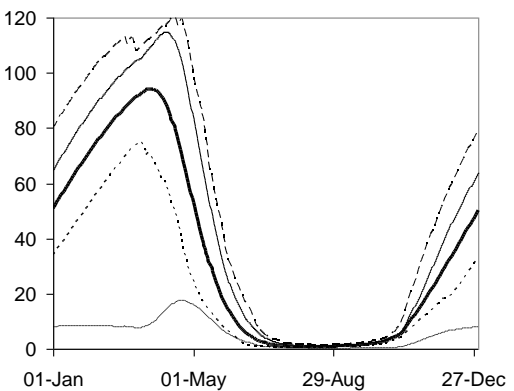

c) Astana

Figure 2 Model output for SMP effluent BOD concentrations with standard design at selected sites

Longer discharge period. Table 3 shows results for model runs with discharge from the 95\% ile value for the first day with effluent BOD concentration less than $20 \mathrm{mg} \mathrm{l}^{-1}$, up to 30 October. Discharging from an earlier date over a longer period has little effect on the average performance or on the earliest and latest date on which the quality is acceptable: one reason is that the influent from the FP is also of good quality in this period. Advantages of an earlier discharge are a reduced pond area, leading to lower evaporation losses and increased availability for potential reuse.

The reduction in pond size seen in Table 3 is mainly due to removal of the need to provide storage for water discharged during the summer period, but may also be due to climatic factors. Figure 3 shows model output for pond depths for Turkestan, Petropavlovsk and Yakutsk. At sites with high evaporation, with a standard design the maximum depth that determines pond size occurs early in the year (e.g. mid-May in Turkestan) and levels fall thereafter. Earlier discharge decreases the depth range at the time of emptying, and thus increases volume utilisation. Further north, the maximum depth occurs immediately before 
emptying. In Astana, for example, depth is determined by a small number of years with relatively high rainfall in the late spring season: these account for an additional $175 \mathrm{~mm}$ of depth which, because of the limit on maximum working depth, contribute approximately $7 \%$ to the pond area. Similarly in Petropavlovsk and Ulan Ude the majority of both precipitation and variability in it occurs in summer, so an extended discharge period has a major effect on the required depth (Figure 3). In Yakutsk variability in depth is relatively small, but even so precipitation events affect the maximum value: the greatest depth is determined by an unusually wet June in 1984, not itself the wettest year.

Table 3 Model output for discharge from first acceptable day to 30 October

\begin{tabular}{|c|c|c|c|c|c|c|}
\hline Site & \multicolumn{3}{|l|}{ Discharge } & $\begin{array}{c}\text { Area } \\
F P+S M P\end{array}$ & Depth range* $^{\star}$ & \multirow[t]{2}{*}{$\%$ for use } \\
\hline Khorog & 95\%ile & 95\%ile & no. of days & ha & $\mathrm{m}$ & \\
\hline Khorog & 09-May & 02-Dec & 207 & 13.2 & 0.58 & $64 \%$ \\
\hline Ashkhabad & 22-Mar & 16-Dec & 269 & 11.0 & 0.43 & $70 \%$ \\
\hline Yerevan & 27-Apr & 12-Dec & 229 & 12.0 & 0.38 & $67 \%$ \\
\hline Bishkek & 16-Apr & 28-Nov & 226 & 12.8 & 0.41 & $65 \%$ \\
\hline Turkestan & 16-Apr & 27-Nov & 225 & 12.1 & 0.33 & $67 \%$ \\
\hline Atyrau & 14-May & 20-Nov & 190 & 12.9 & 0.26 & $65 \%$ \\
\hline Aktyubinsk & 27-May & 10-Nov & 167 & 14.6 & 0.31 & $60 \%$ \\
\hline Astana & 05-Jun & 08-Nov & 156 & 15.0 & 0.36 & $59 \%$ \\
\hline Ulan Ude & 13-Jun & 30-Oct & 139 & 14.8 & 0.18 & $60 \%$ \\
\hline Petropavlovsk & 09-Jun & 07-Nov & 151 & 15.2 & 0.34 & $58 \%$ \\
\hline Krasnoyarsk & 08-Jun & 09-Nov & 154 & 15.5 & 0.30 & $58 \%$ \\
\hline Yakutsk & 25-Jun & 16 -Oct & 113 & 16.7 & 0.23 & $54 \%$ \\
\hline
\end{tabular}

${ }^{*}$ Last $=$ last day with effluent BOD $<20 \mathrm{mg} \mathrm{l}^{-1}$. Depth range = range in max-min values of annual maximum depth

Other modifications. Various different strategies can be adopted to influence the volume of water available and the date at which it reaches the nominal standard for discharge or re-use. One option is to change the pond depth: if the working depth is maintained while the maximum and minimum are increased, this effectively retains a volume of treated water within the pond at the end of summer to provide buffering and dilution for the incoming wastewater. Table 4 illustrates the effect of increasing the maximum and minimum depth, for a working depth of $2 \mathrm{~m}$, using Turkestan and Astana as examples. The result is to bring the earliest discharge date slightly forward, and the final date back. In practice there may be little use for water in November-December in these regions, if air temperatures are below freezing. Table 5 shows the effect of choosing a fixed end-date for the discharge, reflecting different potential options for reuse or disposal, on the earliest start date, the pond area and the re-use potential, for two depth ranges. Once again the earliest start date is brought forward, by a relatively small margin: a maximum of 11 days for Astana and 14 for Turkestan, for a change in end date of 4-5 months. The earliest start date shown for Turkestan corresponds to the time at which water might be of use, for example, in spring pre-irrigation. In this case, the tradeoff for an earlier start date is a reduced proportion of water potentially available for reuse.

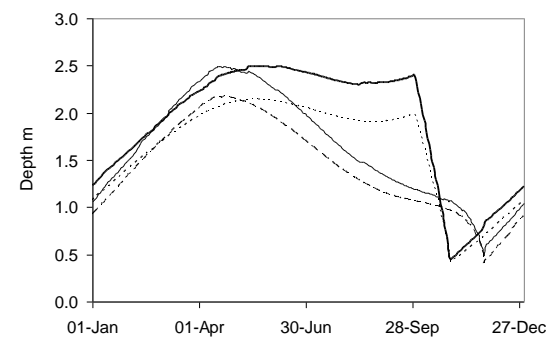

a) Turkestan

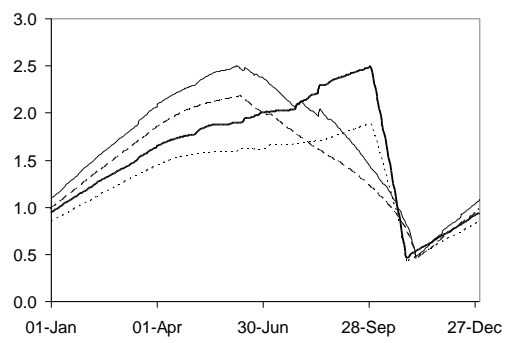

b) Petropavlovsk

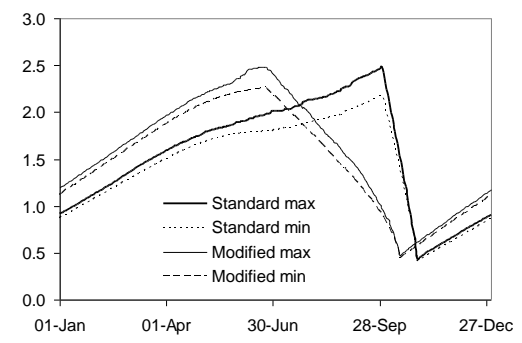

c) Yakutsk

Figure 3 Maximum and minimum SMP depths at selected sites for standard design and modified design with maximum discharge period (as in Table 3) 
Table 4 Model output for different maximum depths with working depth $2 \mathrm{~m}$

\begin{tabular}{|c|c|c|c|c|c|c|c|c|}
\hline SMP max depth & Turkestan & & & & Astana & & & \\
\hline$m$ & Start (95\%ile) & End (95\% ile) & Area (ha) & $\%$ for use & Start (95\%ile) & End (95\%ile) & Area (ha) & $\%$ for use \\
\hline 2.50 & 16-Apr & 27-Nov & 7.1 & $55 \%$ & 05-Jun & 08-Nov & 10.6 & $71 \%$ \\
\hline 3.00 & 16-Apr & 10-Dec & 6.4 & $57 \%$ & 02-Jun & 18-Nov & 9.7 & $73 \%$ \\
\hline 3.50 & 13-Apr & 19-Dec & 5.9 & $59 \%$ & 30-May & 27-Nov & 9.1 & $74 \%$ \\
\hline 4.00 & 11-Apr & 27-Dec & 5.5 & $61 \%$ & 26-May & 19-Nov & 8.6 & $75 \%$ \\
\hline
\end{tabular}

Table 5 Model output for chosen discharge end-date with working depth $2 \mathrm{~m}$

\begin{tabular}{|c|c|c|c|c|c|c|c|c|}
\hline \multirow{2}{*}{$\begin{array}{c}\text { SMP max depth } \\
m \\
\end{array}$} & \multicolumn{4}{|l|}{ Turkestan } & \multicolumn{4}{|l|}{ Astana } \\
\hline & Start (95\%ile) & End (95\%ile) & Area (ha) & $\%$ for use & Start (95\%ile) & End (95\%ile) & Area (ha) & $\%$ for use \\
\hline \multirow[t]{5}{*}{2.50} & 16-Apr & 27-Nov & 7.1 & $55 \%$ & 05-Jun & 08-Nov & 10.0 & $72 \%$ \\
\hline & 14-Apr & 30-Oct & 8.5 & $49 \%$ & 04-Jun & 30-Oct & 10.5 & $71 \%$ \\
\hline & 12-Apr & 30-Sep & 9.4 & $46 \%$ & 01-Jun & 30-Sep & 12.0 & $69 \%$ \\
\hline & 11-Apr & 30-Aug & 9.7 & $45 \%$ & 30-May & 30-Aug & 13.0 & $67 \%$ \\
\hline & 11-Apr & 31-Jul & 9.4 & $46 \%$ & 30-May & 31-Jul & 14.3 & $64 \%$ \\
\hline \multirow[t]{6}{*}{4.00} & 11-Apr & 27-Dec & 5.5 & $61 \%$ & & & - & - \\
\hline & 07-Apr & 30-Nov & 6.8 & $56 \%$ & 26-May & 19-Nov & 9.2 & $74 \%$ \\
\hline & 03-Apr & 30-Oct & 8.1 & $51 \%$ & 24-May & 30-Oct & 10.2 & $72 \%$ \\
\hline & 30-Mar & 30-Sep & 8.8 & $48 \%$ & 21-May & 30-Sep & 11.8 & $69 \%$ \\
\hline & 28-Mar & 30-Aug & 9.1 & $47 \%$ & 18-May & 30-Aug & 12.8 & $67 \%$ \\
\hline & 28-Mar & 31-Jul & 9.0 & $47 \%$ & 17-May & 31-Jul & 14.2 & $65 \%$ \\
\hline
\end{tabular}

The above examples assume a FP pond depth of $1 \mathrm{~m}$ and a BOD loading rate of $40 \mathrm{~kg} \mathrm{ha} \mathrm{h}^{-1}$ day $^{-1}$. Table 6 and Figure 4 show the effect of changing the FP area and loading rate while keeping a depth of $1 \mathrm{~m}$, using Astana as an example. There is a significant effect on the earliest date for discharge, once again at the expense of water availability as evaporation losses rise with increasing area. For FP areas of 6.7 and 10 ha, the system is moving towards ponds of equal sizes, but with intermittent discharge: a sort of hybrid between the classic cold and temperate climate designs.

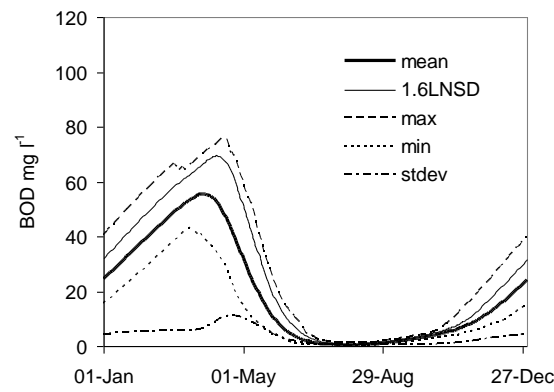

a) $20 \mathrm{~kg} \mathrm{BOD} \mathrm{ha}^{-1} \mathrm{day}^{-1}$

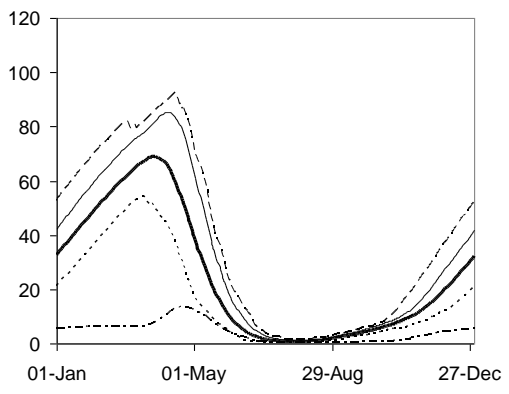

b) $30 \mathrm{~kg} \mathrm{BOD} \mathrm{ha}^{-1}$ day $^{-1}$

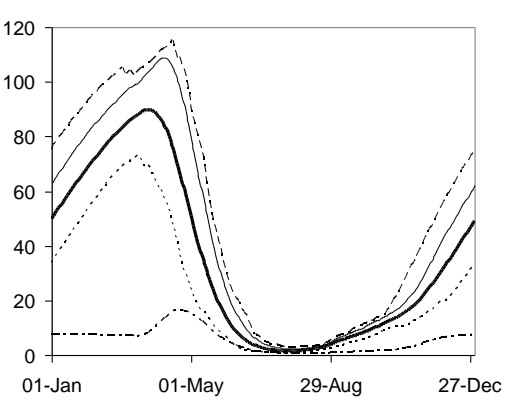

c) $60 \mathrm{~kg} \mathrm{BOD} \mathrm{ha}^{-1} \mathrm{day}^{-1}$

Figure 4 Astana SMP effluent BOD for discharge to 30 August at different FP loading rates $(2.5 \mathrm{~m})$

Table 6 Model output for Astana with discharge to 30 August at different FP loading rates

\begin{tabular}{|c|c|c|c|c|c|c|c|}
\hline FP loading rate & FP area & SMP max dep & $2.5 \mathrm{~m}$ & & SMP max dep & $4 \mathrm{~m}$ & \\
\hline $\mathrm{kg} \mathrm{BOD} \mathrm{ha}^{-1}$ day $^{-1}$ & ha & Start (95\%ile) & Area (ha) & $\%$ for use & Start (95\%ile) & Area (ha) & $\%$ for use \\
\hline 20 & 3.3 & 02-Jun & 16.3 & $70 \%$ & 22-May & 16.1 & $70 \%$ \\
\hline 30 & 5.0 & 30-May & 18.0 & $67 \%$ & 18-May & 17.8 & $67 \%$ \\
\hline 40 & 6.7 & 28-May & 19.6 & $64 \%$ & 16-May & 19.5 & $64 \%$ \\
\hline 60 & 10.0 & 23-May & 22.8 & $58 \%$ & 11-May & 22.8 & $58 \%$ \\
\hline
\end{tabular}

\section{Inter-annual variation}

The above examples indicate how it may be possible significantly to influence discharge dates and/or volumes of water available. From the results shown and from further analysis (not reported here), however, it is clear that variability between years in operating and 
performance parameters is a key issue. Some examples are given above for pond depth; more examples for effluent quality are presented in Figure 5. Figure 5a shows FP effluent BOD for the years 1934 and 1995 for Astana (standard design): while values in late summer are similar, there is a one-month difference in the date at which the wastewater first reaches a steady-state condition. Figure 5b shows SMP effluent BOD for discharge from 27 April - 30 October for the whole dataset for Erevan (Table 3): the wide range is clearly seen, as is the exceptionally cold winter of 1933.

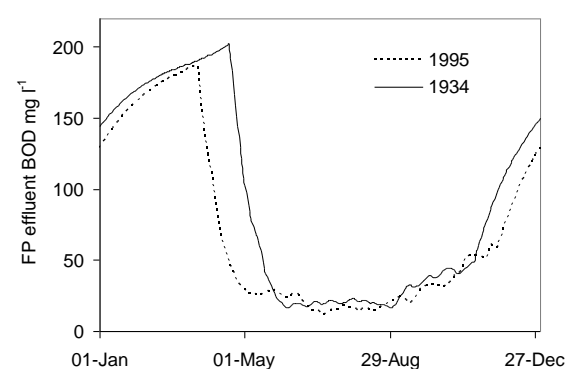

a) Astana FP BOD

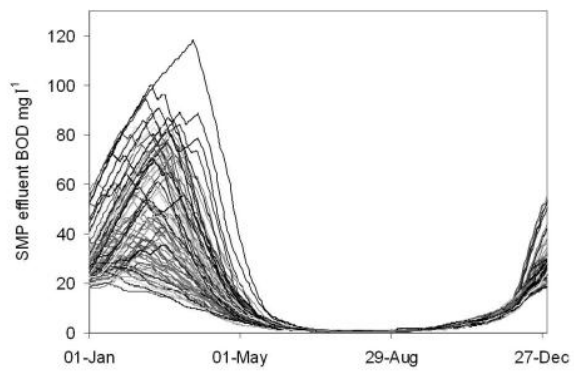

b) Yerevan SMP BOD (all years)

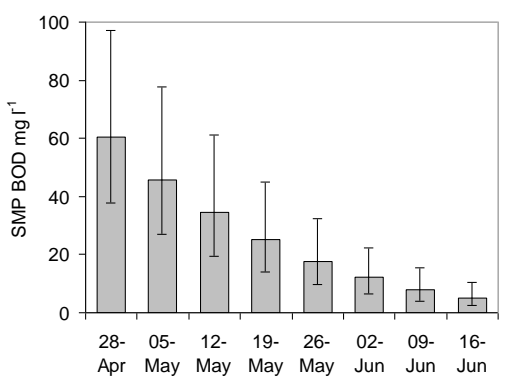

c) Astana SMP BOD

Figure 5 Examples of annual variability in output parameters

The problem of annual variability is particularly acute if it is desired to bring forward the date of first discharge. Not only does the value of the mean effluent concentration rise steeply for earlier dates, but the variability also increases, with a sharp rise in standard deviation during the spring period. This is a direct consequence of annual variation in climate parameters, and can be clearly seen for the cases in Figures 2, 4 and 5b. Figure 5c gives a further example, showing BOD in Astana SMP on the first day of discharge, for discharge from a range of dates to 30 October. These examples indicate the variability of these systems, and suggest that careful management may be needed to ensure acceptable discharge quality. If it is essential to guarantee that water of suitable quality will be available early in the year, it may be necessary to adopt other strategies, such as the use of alternating parallel SMPs to provide separate storage for treated wastewater.

\section{Model limitations and development}

The limitations of the modelling approach are discussed briefly in Heaven et al (2005). Sensitivity analysis and statistical parameters are dealt with in another paper (Salter et al., in preparation), and are not considered here. In summary, the model oversimplifies pond behaviour, and tends to give SMP effluent concentrations that are too low in summer. Choice of parameters is based on mid-range values from Mara (1976), with very limited validation on an experimental scale in Almaty, Kazakhstan $\left(43.2^{\circ} \mathrm{N}, 76.9^{\circ} \mathrm{E}\right)$. Further questions concern validity across a wide geographical range, in particular for places like Ashkhabad and Bishkek where ponds may not freeze every year. In the current application, the method of determining SMP area from the maximum depth according to historic data is unsatisfactory, as it may be influenced by extreme values: a more sophisticated approach would consider the distribution of depths. With high variability, 99\%ile values may be more appropriate than the 95\% ile conventionally used in wastewater treatment. Despite these points, it is clear that modelling is potentially a powerful design tool for improved performance and that further research providing relevant parameter and validation data would be of great value.

\section{CONCLUSIONS}

The results of the modelling work confirm that the standard North American design with 12 
months storage is robust. There is little or no carry-over in performance from year to year, due to the long period of treatment in summer which allows steady-state conditions to develop. This means the fact that continental climates can experience sequences of wet or dry and hot or cold years is unlikely to be critical for design. The standard design and operating protocol may be conservative in many locations, however, and there is potential for modification to reduce the overall size of the pond system and increase the volume of treated water available for potential reuse. Possible options include changing the discharge period; changing maximum and minimum depths to retain treated water in the pond over the winter period; and altering the facultative pond loading. In most cases these involve a trade-off between discharge date and water availability. If design and operating protocols are to be modified, however, annual variability in climate parameters will have a significant effect, in particular on the date at which the treated wastewater is likely to meet appropriate standards for discharge or re-use: the earlier the discharge, the greater the variability in effluent quality. To eliminate the effect of year-on-year variations, it may be necessary to consider alternatives such as separate storage of treated water over the winter period. Skilful management may be needed if the performance of these systems is to be maximised. While current models require development, it is clear modelling could provide tools and guidelines that would allow the design of continental climate WSPs to be more closely tailored to regional and local conditions.

\section{REFERENCES}

Allen, R.G., Raes, D., Pereira, L., and Smith, M (1998). Crop Evapotranspiration. FAO Irrigation and Drainage Paper no. 56. Food and Agriculture Organization of the United Nations, Rome.

Heaven, S., Banks, C.J., Pak, L.N., and Rspaev, M.K. (2005). Wastewater reuse in central Asia: implications for the design of pond systems. IWA Conference on Wastewater Reclamation \& Reuse, Jeju, Korea, 8-11 November.

IWMI (2006). International Water Management Institute On-Line Climate Summary Service, http://www.iwmi.cgiar. org/WAtlas/AtlasQuery.htm (accessed June 2006).

Mara, D.D. (1976). Sewage treatment in hot climates. John Wiley \& Sons, Chichester, UK.

Prince, D.S., Smith D.W., and Stanley, S.J. (1995). Performance of lagoons experiencing seasonal ice cover. Water Environment Research 67(3), 318-326.

RIHMI-WDC (2006). All-Russia Research Institute of Hydrometeorological Information World Data Centre. http:// meteo.ru/data/emdata.htm (accessed June 2006).

Salter, A.M., Heaven, S., and Clarke, D. (in preparation). A model for continental climate waste stabilisation ponds.

US EPA (1983). Design Manual: Municipal Wastewater Stabilization Ponds. Report 625/183-015, US Environmental Protection Agency, Cincinnati, Ohio. 